\title{
Influence of racial origin on admission rates of patients with suspected myocardial infarction in Birmingham
}

\author{
P J Lowry, P Lamb, R D S Watson, K E Ellis, S P Singh, W A Littler, B L Pentecost
}

\begin{abstract}
All patients with suspected myocardial infarction admitted to hospital in four Birmingham health districts were studied to test the hypothesis that Asian patients would be overrepresented and Caribbean patients underrepresented compared with the indigenous population. One thousand four hundred and ninety six patients had a final diagnosis of myocardial infarction or severe angina pectoris. The relative risk of admission for Asian men compared with white men aged $45-64$ years was $2 \cdot 65(95 \%$ confidence interval $2 \cdot 20$ to $3 \cdot 19$ ) and the risk for Asian men was high for both myocardial infarction and ischaemia when analysed separately. The relative risk of admission for Caribbean men compared with
\end{abstract} white men was $0.53(95 \%$ CI 0.33 to 1.20$)$. The relative risk for Asian women compared with white women in the same age group was $2.58(95 \%$ CI 1.68 to 3.96$)$, but this was due to an excess of admissions diagnosed as ischaemia rather than infarction in the Asian women. For Caribbean and white women the risk of admission was the same, although significantly fewer Caribbean women were admitted with myocardial infarction. The study was undertaken in 1986-87 and population data had to be derived from the 1981 census. The resident population changed in those five years and so the results were recalculated making allowances for these changes in the health districts involved. Based on these data the admission rate for Asian men with suspected myocardial infarction aged 45-64 was nearly twice that for white men (1.8): the relative risk of admission for Asian men compared with white men was 2.04 (95\% CI 1.53 to 2.18). For Caribbean men the relative risk compared with white men was $0.45(95 \%$ CI 0.29 to 0.71). For Asian women the relative risk of admission calculated from the adjusted census data resembled that in white women aged 45-64 years. The relative risk for admission with coronary heart disease in Asians is higher than expected from previous reported work; one possible explanation for this is that the Asian population resident in the area under study was larger than estimated. The single major difference in risk factors was the high prevalence of diabetes mellitus in Asians (19.5\% compared with $8 \cdot 3 \%$ for white residents) but this did not wholly account for the excess of admissions from the Asian community.

Though as a general rule emigrants are healthier than the population left behind ${ }^{1}$ their mortality from cardiovascular disease tends to be intermediate between that of their home country and the land of adoption. ${ }^{2}$ Within one or two generations, however, the pattern of mortality changes towards that of the adopted country, as shown by westernised Japanese-Americans. ${ }^{3}$ Although the incidence of coronary artery disease in India and Pakistan is not well documented, these rates are believed to be lower than those found in Britain so that the high mortality from coronary disease seen in Asians exceeds both that of the indigenous white population in Britain and their region of origin. ${ }^{4-6}$ High mortality from coronary disease in Indian migrants has also been reported from other parts of the world ${ }^{78}$ whereas the prevalence of coronary artery disease in black people both in the West Indies and in their country of adoption is less ${ }^{19}$; none the less in the United States of America mortality from coronary artery disease in black men is similar to that of white men, though it may be excessive in black women. ${ }^{1011}$ The city of Birmingham has large Asian and Caribbean communities and offered the opportunity to observe whether the expected excess of coronary disease in Asians and the anticipated low prevalence in Caribbeans compared with the indigenous white population were reflected in different hospital admission rates for suspected myocardial infarction and to explore reasons for any observed differences.

Patients and methods

Patients were studied from 1 July 1986 to 30 June 1987 in five hospitals in four health districts with a total population of 0.84 million. Only patients under the age of 65 years and of Cardiovascular Medicine, East Birmingham Hospital, Bordesley Green East, Birmingham B9 5ST

Accepted for publication 12 February 1991

General Hospital,
Birmingham
P J Lowry
P Lamb
B L Pentecost
Dudley Road Hospital,
Birmingham
R D S Watson
K E Ellis
S P Singh
Department of
Cardiovascular
Medicine, East
Birmingham Hospital
W A Littler
Correspondence to
Dr P Lowry, Department
of Cardiovascular Medicine,
East Birmingham Hospital,
Bordesley Green East,
Birmingham B9 5ST.
Accepted for publication
12 February 1991


normally resident within the health districts were included. Our data relate to all patients in whom a diagnosis of myocardial infarction was suspected and in whom the final diagnosis was one of cardiac pain caused by coronary disease. Myocardial infarction was confirmed by the development of typical electrocardiographic changes and/or a rise in cardiac enzymes to at least twice the upper limit of the normal range for the hospital concerned. If infarction was not confirmed and the diagnosis of coronary ischaemia could not be substantiated patients were excluded from the study. Details of age, sex, occupation, address, ethnic origin, risk factors, and past medical history were recorded on admission. Details of blood cholesterol (if measured on day 1 of admission), final outcome, and final diagnosis as assessed by the medical team in charge of the patient were recorded after discharge, death, or transfer from hospital. The information was collected by doctors and nurses working on the coronary care units or the emergency admission units.

The estimate of the population at risk was calculated from the 1981 census using Small Area Statistics which records the number of persons usually resident in private households whether born inside or outside the United Kingdom categorised by age and sex of residents, and by birthplace of head of household for each electoral ward contained within the four health districts in the study. ${ }^{12}$ Narrower age bands of five or 10 years are not available for individual wards. The white group included all those born in Great Britain, Northern Ireland, and the Republic of Ireland, the Asian group included all those born in the Indian subcontinent, and the Caribbean group all those born in the West Indies. Total population statistics were calculated for the three racial groups according to sex, and separate totals were obtained for those between the ages of 30 and 44 years, and 45 and 64 years. The age and sex structure of the three communities differed considerably with a relative excess of men in the Asian group; for example, in the 4564 age group, the male:female ratio was 0.98:1 for white residents, 1.1:1 for Caribbeans, and $1 \cdot 6: 1$ for Asians. In view of these differences most results are expressed according to sex. The Asian and Caribbean populations are young with very few members over the age of 65 years unlike the aging white population (fig 1). In the five years since the population census, the numbers of Asians and Caribbeans entering the 30-44 age group have been greater than the number leaving the 45-64 age group. In view of this, the admission rate with myocardial infarction or myocardial ischaemia was calculated in two ways; firstly on the population data of 1981 and secondly on an adjusted population base. The adjustment assumed that between 1981 and 1986 one third of the people in the $30-44$ age group moved into the $45-64$ age group. It was also assumed that one quarter of the white population moved out of the 45-64 age group, but because the Asian and Caribbean populations had few people in the older groups, none was assumed to have moved out of the 45-64 age group. This calculation would almost cer-

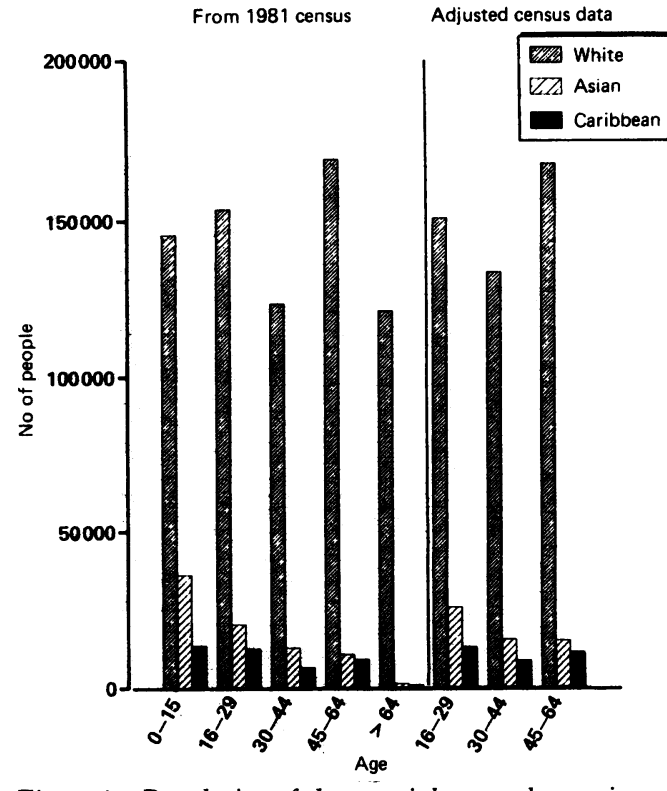

Figure 1 Population of three racial groups by age in years from 1981 census and according to adjusted census data.

tainly result in an overestimate of the Asian and Caribbean population at risk (fig 1 ). The adjustment gave an estimated population of 83481 white men, 9200 Asian men, and 5923 Caribbean men, and 85427 white women, 5930 Asian women, and 5356 Caribbean women in the 45-64 age group. There are no good data on changes in the number of Birmingham citizens from the New Commonwealth and Pakistan (NCWP), or indeed of any other city or district within the United Kingdom, between 1981 and 1986. One estimate suggests an annual national increase in citizens of NCWP origin of 90000 , mostly from South Asia. ${ }^{13}$ Two thirds of the increase is accounted for by births; when allowance is made for deaths the figure is approximately 140000 new migrants over the five years. Between 1983 and 1985 the West Midlands contained an average of $20 \%$ of the citizens of South Asian origin living within the United Kingdom. ${ }^{13}$ If it is assumed that a similar proportion of the new migrants entered this region a population increase of 28000 would be predicted. Approximately $25 \%$ of the West Midlands NCWP population was housed in Birmingham ${ }^{14}$ suggesting a possible increase of around 12300 even though we know that the overall population of Birmingham has fallen by 20000 during the same five year period. ${ }^{15}$ If the migrants had an age and sex distribution similar to the existing population an increase of around 1600 between the ages of 45 and 64 would be expected of whom two thirds would be men-about 1070. This is likely to be an overestimate because the expected pattern of migration was thought to involve predominantly the female partners of those already within the United Kingdom. This would finally adjust the figure for Asian men aged 45-64 to 10270 and that for women to 6460 .

Differences between the populations based on actual numbers were assessed by the $\chi^{2}$ test and $95 \%$ confidence intervals $(95 \% \mathrm{CI})$ for relative risk were calculated. Differences in prevalence of risk factors were assessed by the 
Table 1 Demographic data

\begin{tabular}{|c|c|c|c|c|c|c|c|c|c|c|c|c|}
\hline \multirow[b]{3}{*}{ Group } & \multirow{2}{*}{\multicolumn{2}{|c|}{ Population 1981 census }} & \multirow{2}{*}{\multicolumn{2}{|c|}{ Admissions }} & \multirow{2}{*}{\multicolumn{2}{|c|}{$\begin{array}{l}\text { Number of } \\
\text { confirmed } \\
\text { infarctions }\end{array}$}} & \multicolumn{4}{|c|}{ Number aged 45-64 years } & \multirow{2}{*}{\multicolumn{2}{|c|}{ Deaths }} \\
\hline & & & & & & & \multicolumn{2}{|l|}{ Male } & \multicolumn{2}{|l|}{ Female } & & \\
\hline & Male & Female & Male & Female & Male & Female & Population & Admissions & Population & Admissions & (male) & (female) \\
\hline $\begin{array}{l}\text { White } \\
\text { Asian } \\
\text { Caribbean }\end{array}$ & $\begin{array}{r}348082 \\
44426 \\
20875\end{array}$ & $\begin{array}{r}366023 \\
37746 \\
21991\end{array}$ & $\begin{array}{r}897 \\
184 \\
24\end{array}$ & $\begin{array}{r}391 \\
36 \\
6\end{array}$ & $\begin{array}{r}606 \\
122 \\
15\end{array}$ & $\begin{array}{r}232 \\
15 \\
3\end{array}$ & $\begin{array}{r}82806 \\
7024 \\
5005\end{array}$ & $\begin{array}{r}596 \\
134 \\
19\end{array}$ & $\begin{array}{r}87488 \\
3782 \\
4090\end{array}$ & $\begin{array}{r}206 \\
23 \\
4\end{array}$ & $\begin{array}{c}115(73) \\
15(14) \\
1(0)\end{array}$ & $\begin{array}{c}71(42) \\
13(12) \\
1(0)\end{array}$ \\
\hline
\end{tabular}

standard error of the difference between the proportions of each risk factor between the groups. Cholesterol concentrations were assessed by Student's unpaired $t$ test.

\section{Results}

We studied 1496 patients judged to have a final diagnosis of myocardial infarction or severe angina pectoris. Table 1 records the relevant demographic data for the study.

\section{ALL MALE PATIENTS}

The indigenous white male population had 897 admissions with suspected myocardial infarction, an admission rate of $258 / 100000$ white population. One hundred and eighty four Asian men were admitted, an admission rate of $414 / 100000$, and from the Caribbean community only 24 men were admitted, an admission rate of $115 / 100000$ population. Compared with the white population only 114 Asian admissions would have been expected but there were $184(p<0.001)$; this contrasts with 53 expected admissions from the Caribbean community, where there were only $24(\mathrm{p}<0.001)$.

The admission rate for definite myocardial infarction was $71 / 100000$ for white residents, 275/100 000 for Asian residents, and 72/ 100000 for Caribbean residents. There was a

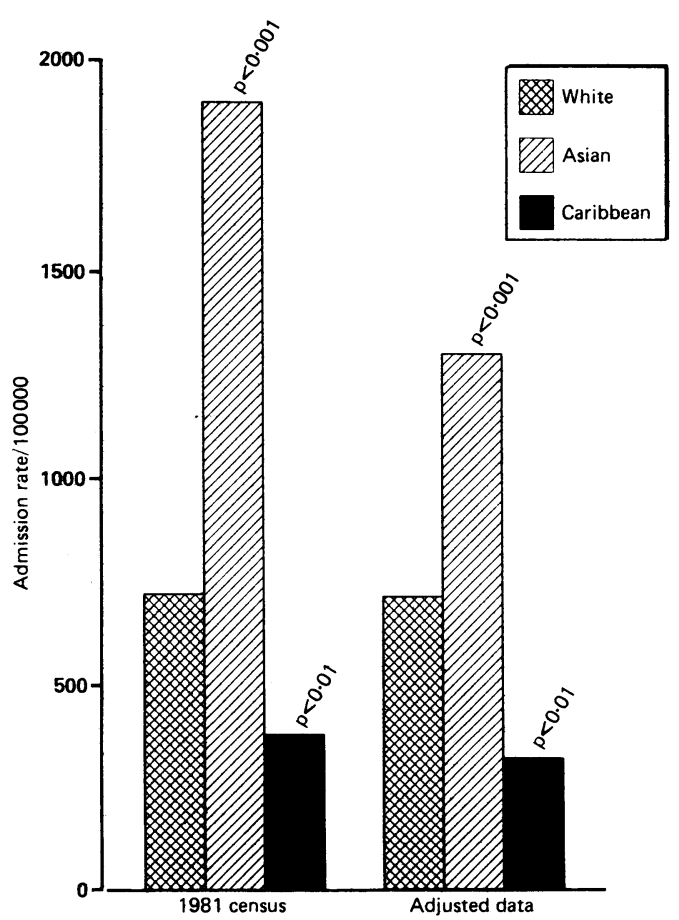

Figure 2 Admission rate for suspected myocardial infarction in each racial group/100 000 population aged 45-64 years according to 1981 census data and adjusted population data for men. significant difference in the admission rate between Asian residents and white residents $(\mathrm{p}<0.001)$.

\section{MEN AGED 45-64 YEARS}

Most patients admitted in the study were in the $45-64$ age group $(66 \%)$. For men in this age group, the differences in admission rate per 100000 population when either the 1981 census data or the adjusted census data were used remained highly significant (fig 2 ). With the 1981 census data, there were $720 / 100000$ admissions in the white group, 1908/100 000 in the Asian group, and 380/100 000 admissions in the Caribbean group. The adjusted census data gave admission rates of 714/100 000 for white residents, $1304 / 100000$ for Asian residents, and 321/100000 for Caribbean residents. The admission rate per 100000 population from the Asian community was $2 \cdot 7$ times the admission rate from among the white residents $(p<0.001)$ calculated from the 1981 census data and 1.8 times the admission rate calculated from the adjusted census data $(p<0.001)$. The relative risk of admission from suspected myocardial infarction for Asian men compared with white men was $2.65(95 \%$ CI 2.20 to 3.19 ) when the 1981 census data were used and 2.04 (95\% CI 1.53 to 2.18 ) when the adjusted population data were used. The

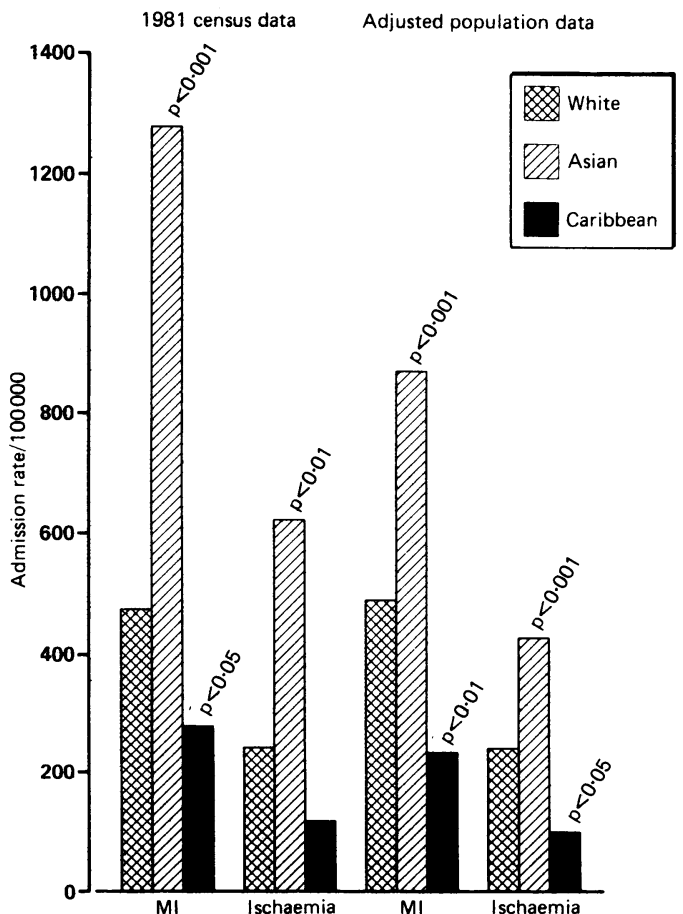

Figure 3 Admission rate for men in each racial groupl 100000 population aged 45-64 years for confirmed myocardial infarction (MI) and acute myocardial ischaemia according to 1981 census data and adjusted population data. 
Figure 4 Admission rate for suspected myocardial infarction in each racial group/100 000 population aged 45-64 years according to 1981 census data and adjusted population data for women.

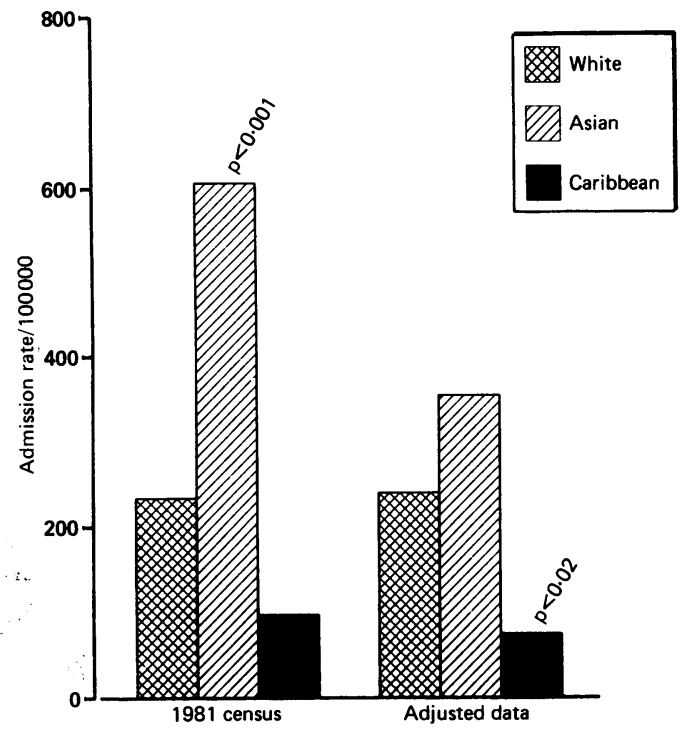

Caribbeans were underrepresented compared with the white community when the 1981 census data were used $(p<0.01)$ and when the adjusted data were used $(\mathrm{p}<0.001)$. For Caribbeans, the relative risk compared with white residents was $0.53(95 \%$ CI 0.33 to 1.20 ) when the 1981 census data were used and 0.45 (95\% CI 0.29 to 0.71$)$ when the adjusted population data were used.

When the results for myocardial infarction and myocardial ischaemia are analysed separately the same pattern emerges (fig 3): 393 white residents, 90 Asians, and 14 Caribbeans had a definite infarct. The admission rate per 100000 for definite myocardial infarction was 475 for white residents, 1281 for Asians, and 280 for Caribbeans when the 1981 census data were used, and 491,876 , and 236 respectively when the adjusted census data were used. The corresponding admission rates per 100000 for ischaemia were 245,626 , and 120 ; and 243,428 , and 101. For myocardial infarction and myocardial ischaemia, when both the 1981 census data and the adjusted data were used, the admission rate from the Asian community was higher than expected when compared with the white community $(p<0.001$ for each comparison). The relative risk of being admitted with a definite myocardial infarct for Asian men aged 45-64 compared with white men was $2 \cdot 70(95 \%$ CI $2 \cdot 15$ to $3 \cdot 39)$ when the 1981

Figure 5 Admission rate for women in each racial group 100000 population aged 45-64 years for confirmed myocardial infarction (MI) and acute myocardial ischaemia according to 1981 census data and adjusted population data.

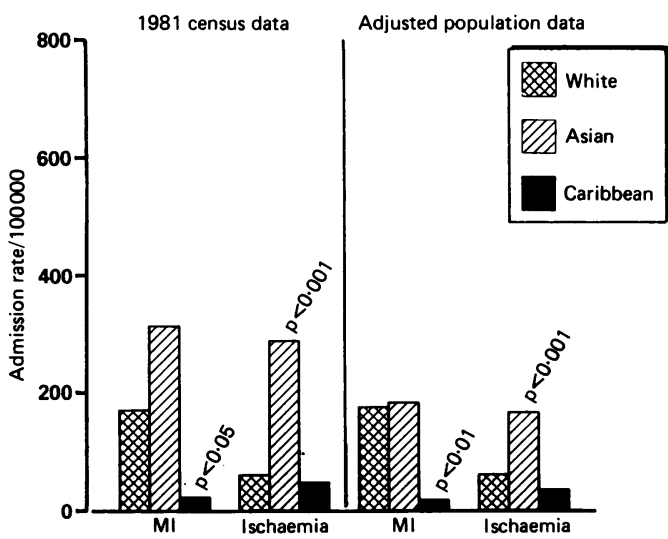

census data were used and $1.86(95 \%$ CI 1.48 to 2.33 ) when the adjusted population data were used. In the Caribbean community the difference was not significantly different for ischaemia alone when the 1981 census data were used but it was significantly less than expected compared with the indigenous white population for myocardial infarction when the 1981 census data were used $(p<0.05)$ and for myocardial infarction $(\mathrm{p}<0.01)$ and ischaemia $(\mathrm{p}<0.05)$ when the adjusted census data were used. The relative risk of myocardial infarction in Caribbeans compared with the white residents when the census data for 1981 were used was $0.59(95 \% \mathrm{CI} 0.35$ to 1.00$)$ and when the adjusted data were used it was 0.50 $(95 \%$ CI 0.29 to 0.85$)$. The case fatality rate per 100 admissions with suspected myocardial infarction in men aged 45-64 was not significantly different in the Asian and white groups (table 1).

\section{ALL FEMALE PATIENTS}

The admission rate per 100000 for white women was 107, and this did not differ significantly from the admission rate for Asian women (95). The admission rate (27) for Caribbean women was significantly lower than that for white women $(p<0.001)$. Similar findings were seen in those patients admitted with definite infarction: the admission rate was 63 for white women, 40 for Asian women, and 14 for Caribbean women ( $p<0.001$ for Caribbean women compared with white women).

\section{WOMEN AGED 45-64}

For the 1981 census data the admission rate per 100000 for Asian women was higher than for white women $(608 v 235(\mathrm{p}<0.001))$; the relative risk of admission was 2.58 (95\% CI 1.68 to 3.96 ) (fig 4). The admission rate for the Caribbean group (98) was not significantly different. When the adjusted census data were used the admission rate in Asian women was not significantly different from that in white women. The admission rate for Caribbean women was significantly less (75) than that in white women $(\mathrm{p}<0.02)$.

There was no significant difference in admission rates for definite myocardial infarction between Asian and white women either for the 1981 census data or the adjusted data (fig 5). Significantly fewer Caribbean women were admitted ( $p<0.05)$.

According to the 1981 census data significantly more Asian women than white women were admitted with myocardial ischaemia $(p<0.001)$. The case fatality rate was similar in all three groups.

\section{RISK FACTORS}

Sixty per cent of the Caribbean patient group had hypertension: this prevalence of hypertension was significantly greater than that found in either the white or the Asian groups $(p<0.001)$; a high prevalence of diabetes mellitus was also found in the Caribbean group although this difference was not significant (table 2). Of the Asian patients 19.5\% had diabetes mellitus, a significantly higher pre- 
Table 2 Numbers of patients admitted with risk factors (percentage of total admissions)

\begin{tabular}{|c|c|c|c|c|c|c|}
\hline & Hypertension & $\begin{array}{l}\text { Diabetes } \\
\text { mellitus }\end{array}$ & Smoking & Ex-smoker & $\begin{array}{l}\text { Lifelong } \\
\text { non-smoker }\end{array}$ & $\begin{array}{l}\text { Total number } \\
\text { in group }\end{array}$ \\
\hline $\begin{array}{l}\text { White } \\
\text { All patients } \\
\text { Male (45-64 years) } \\
\text { Female (45-64 years) }\end{array}$ & $\begin{array}{r}278(22 \cdot 3) \\
120(20 \cdot 1) \\
60(29 \cdot 1)\end{array}$ & $\begin{array}{r}103(8 \cdot 3) \\
47(7 \cdot 9) \\
14(6 \cdot 8)\end{array}$ & $\begin{array}{r}588(47 \cdot 1) \\
315(52 \cdot 9) \\
94(45 \cdot 6)\end{array}$ & $\begin{array}{r}381(30 \cdot 6) \\
188(31 \cdot 5) \\
50(24 \cdot 3)\end{array}$ & $\begin{array}{r}256(20 \cdot 5) \\
84(14 \cdot 1) \\
56(27 \cdot 2)\end{array}$ & $\begin{array}{r}1246 \\
596 \\
206\end{array}$ \\
\hline $\begin{array}{l}\text { Asian } \\
\text { All patients } \\
\text { Male (45-64 years) } \\
\text { Female (45-64 years) }\end{array}$ & $\begin{array}{l}56(25 \cdot 5) \\
26(19 \cdot 4) \\
13(56 \cdot 5)\end{array}$ & $\begin{array}{r}43(19 \cdot 5) \\
25(18 \cdot 7) \\
9(39 \cdot 1)\end{array}$ & $\begin{array}{c}104(47 \cdot 3) \\
76(56 \cdot 7) \\
1(4 \cdot 3)\end{array}$ & $\begin{array}{l}32(14 \cdot 5) \\
24(17 \cdot 9) \\
0\end{array}$ & $\begin{array}{l}82(37 \cdot 3) \\
32(23 \cdot 9) \\
22(95 \cdot 7)\end{array}$ & $\begin{array}{r}220 \\
134 \\
23\end{array}$ \\
\hline $\begin{array}{l}\text { Caribbean } \\
\text { All patients }\end{array}$ & $18(60 \cdot 0)$ & $7(23 \cdot 3)$ & $10(33 \cdot 3)$ & $9(30 \cdot 0)$ & $11(36 \cdot 7)$ & 30 \\
\hline
\end{tabular}

valence of diabetes mellitus than in the white patients $(8.3 \%)(p<0.001)$. It is difficult to standardise for this risk factor when the frequency of diabetes in the base population is unknown but the relative risk of admission in non-diabetics can be calculated by referring to the overall population: this gives a relative risk of 2.34 (95\% CI 0.56 to 9.718 ) in Asian men aged 45-64 years compared with white men. For non-diabetic Asian women in this age group the relative risk was $0.85(95 \% \mathrm{CI} 0.50$ to 1.45).

Different smoking trends were observed. The numbers of current smokers were similar but there was a significantly greater proportion of lifetime non-smokers in the Asian group $(p<0.001)$ and a larger number of ex-smokers in the white group $(\mathrm{p}<0.01)$ and West Indian group (NS). The mean (SEM) cholesterol concentration in 384 white patients was 6.68 $(0.33) \mathrm{mmol} / \mathrm{l}$. There were no significant differences between the groups even after adjustment for age. Asian women had a significantly higher prevalence of hypertension and diabetes than Asian men and both white men and women ( $p<0.001$ for all groups).

Although the inpatient Asian population was broadly similar to that of the total Asian community for region of origin, there was a trend towards overrepresentation of Pakistani Moslems and underrepresentation of Indian Hindus and Sikhs (fig 6). The prevalence of diabetes mellitus was similar among patients in all subgroups of the Asian population (between $20 \%$ and $40 \%$ ).

\section{PAST MEDICAL HISTORY}

The only significant difference was that a history of angina was more common in the white group than the Asian group $(p<0.05)$.

Figure 6 Proportion of main Asian ethnic groups in Birmingham: $(A)$ aged $\geqslant 30$ years in the community. (B) aged $\geqslant 30$ years admitted to hospital.

\section{Discussion}

This study confirms a high incidence of coronary events requiring hospital admission in people from the Indian subcontinent living in Britain, which contrasts with the lower incidence seen among West Indians. ${ }^{16}$ This accords with earlier studies from the United Kingdom $^{17-19}$ and other parts of the world, ${ }^{69}$ although the relative risk (2.04) seen for Asian men aged 45-64 was greater than in other studies where it ranged from $1 \cdot 2$ to $1 \cdot 5 .{ }^{17-19}$ This could reflect an inaccuracy in the calculation of the resident Asian population under study. There are major difficulties in obtaining an accurate picture of the racial make up of the population in a large conurbation at any one time. We adjusted the census data on the basis of migration figures but these calculations involve much supposition which cannot be validated. Outmigration - that is members of the Asian community leaving the area since 1981-cannot be calculated but any such reduction in numbers would reduce the population at risk. Immigration, in particular the growth of the Asian population over the five year period since the census was taken, is difficult to calculate. We attempted to allow for this but all the figures can only be likely estimates based on the crude data. ${ }^{13-15}$ We would have preferred to analyse the data in narrower age bands and so reduce error in population shifts by age but no such data are available in Small Area Statistics for political wards. We thought that the error introduced into the denominator by the use of population data for five year age bands either for Birmingham alone or for the whole of the West Midlands would have been greater. The Asian community is substantially younger than the indigenous white population and if five year age bands are not used this difference introduces further inaccuracies. We believe there would be a greater proportion of the population in the lower end of the 45-64 range. We therefore assumed that there was no loss of Asian population from this range in the group aged $\geqslant 65$ years. Both this allowance and the assumption that one third of the population would have moved from the 30-44 years age group, which is probably an overestimate, tend to exaggerate the true population of the Asians aged 45-64 years. Such a bias would tend to underestimate the difference that we found in the admission rates. It might have been helpful to look at comparative data for a disease for which Asians

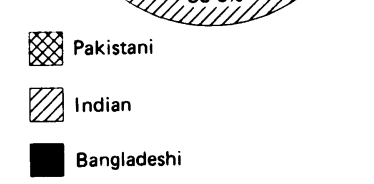


would be expected to have a lower age standardised admission rate than white residents, for example, cancer. However, information on death or diagnosis of cancer on discharge from hospital was not recorded by ethnic origin either on the cancer registry or by the individual health authorities.

The patients in this study were seen in emergency admitting units and coronary care units but a few patients with chest pain were admitted to other wards and included. It is likely that some patients with coronary disease who had a myocardial infarction were not identified as such on presentation and were admitted to wards other than a coronary care unit, the diagnosis becoming apparent later in their hospital stay. Again, these numbers will be small because doctors tend to err on the side of caution when dealing with chest pain-when myocardial infarction is suspected overdiagnosis is more common than underdiagnosis. No account was made of patients seen in the casualty department and sent home. By documenting every patient's address, we have been able to identify and exclude patients living outside the study area, but have been unable to identify patients resident in the area of the study who have been treated in hospitals outside the four health districts involved. This is unlikely to be a large number, however, because of the ambulance policy which is to take all patients with suspected myocardial infarction to the nearest hospital. It is likely that some people who lived within the area were admitted from their place of work situated outside the four districts during the working day but the large contiguous area covered by the four health districts in the study would minimise this source of error.

It is true that the hospital population may not entirely reflect the community prevalence of coronary disease but this study was concerned with the impact on the hospital service of racial variations in the disease.

Asian men had a high admission rate for coronary disease compared with the indigenous white population. Asian women, however, were overrepresented only in the group with ischaemia and it may be that difficulties in communication and understanding have resulted in some women being incorrectly diagnosed; where there was a hard end point of myocardial infarction, there was no increase in admission rate, unlike the results for Asian men. A broad overview of risk factors confirmed that a greater number of Asians are lifetime non-smokers though the prevalence of smoking in Asian men aged 45-64 years was the same as in white men. Unlike white women, very few Asian women smoke. This accords with other studies. $^{2021}$ The high prevalence of diabetes mellitus is not surprising in view of previous reports $^{821}$ and its known prevalence in the Asian community. ${ }^{1822} \mathrm{~A}$ prevalence of diabetes mellitus of approximately $6 \%$ has been reported in Asians aged 45-49 years rising to an excess of $12 \%$ in $60-69$ year old Asians, about five times the rate seen in white people. ${ }^{22}$ Our study found a prevalence of $19 \cdot 5 \%$ diabetes among Asian patients and this may go some way to explain the higher incidence of acute coronary events in this section of the population. The relative risk in non-diabetic Asian men was also high compared with white men. Conversely, Asian women did not have a high relative risk of admission but the prevalence of diabetes was high in the patient group. This suggests that diabetes alone cannot account for the differences in admission rates. If the population estimate is higher than that calculated, however, the prevalence of diabetes mellitus might account for more of the increased risk. As in this study, others have not found high cholesterol concentrations in Asian patients with coronary disease ${ }^{8}$ or in the Asian population $^{19}$; however, only total serum cholesterol was measured and only a third of all patients had their cholesterol measured on admission.

The lower admission rate among people of Caribbean origin described here is compatible with their recorded low mortality for coronary artery disease. Among those who were admitted with suspected myocardial infarction there was a high prevalence of diabetes but numbers were small and did not achieve statistical significance. Hypertension, however, was more prevalent in the Caribbean patients than in the other two groups. This study did not help to clarify why Caribbeans have such a low risk of coronary artery disease.

The admission rate to hespital for confirmed myocardial infarction or myocardial ischaemia among Asian men in Birmingham was higher than that of the indigenous white population. The single major difference in risk factors was the high prevalence of diabetes mellitus in all Asian groups, ${ }^{18}$ a higher prevalence than would be expected in the Asian community. The morbidity resulting from diabetes mellitus and coronary disease represents a considerable problem in the Asian community and this is going to increase as this young population ages and if the attendant high admission rate to hospital continues.

We thank all the nurses and physicians of the coronary care units and emergency admitting units involved in this study.

1 Marmot MG, Adelstein AM, Bulusu L. Cardiovascular mortality among immigrants to England and Wales. mortality among immigrants
Postgrad Med J 1981;57:760-2.

2 Marmot MG, Adelstein AM, Bulusu L. Immigrant mortality in England and Wales 1970-1978. London: HMSO, 1984. in England and Wales 1970-1978. London: HMSO, 1984. 47.

3 Marmot MG, Syme SL. Acculturation and coronary heart disease in Japanese-Americans. Am J Epidemiol 1976; 104:225-47.

4 Coronary heart disease and Asians in Britain. London: Confederation of Indian Organisations (UK) and the Coronary Prevention Group, 1986.

5 Miller GJ, Beckles GLA, Alexis SD, Byam NTD, Price SGL. Serum lipoproteins and susceptibility of men of Indian descent to coronary heart disease. Lancet 1982;ii:200-3.

6 Seedat YK. Hypertension and ischaemic heart disease in Indian people living in South Africa and in India. $S$ Afr Med J 1982;61:965-7.

7 Danaraj TJ, Acker MS, Danaraj W, Ong WH, Yam TB. Ethnic group differences in coronary heart disease in Singapore: an analysis of necropsy records. Am Heart J 1959;58:516-26.

8 Beckles GLA, Miller GJ, Kirkwood BR, Alexis SD, Carson DC, Byjam NTA. High total and cardiovascular disease mortality in adults of Indian descent in Trinidad unexplained by major coronary risk factors. Lancet 1986;i:1298-300.

9 Kraus JF, Borhani NO, Franti CE. Socioeconomic status, ethnicity, and risk of coronary heart disease. $A m J$ 
Epidemiol 1980;111:407-14

10 Gillum RF. Coronary heart disease in black populations. I. Mortality and morbidity. Am Heart $J$ 1982;104:839-51.

11 Johnson JL, Heineman EF, Heiss G, Hames CG, Tyroler HA. Cardiovascular disease risk factors and mortality among black women and white women aged 40-64 years in Evans County, Georgia. Am J Epidemiol 1986;123: 209-20.

12 OPCS. Small area statistics 1981 . Draft tables 8822/8823: $1-84$

13 OPCS. Ethnic minority populations in Great Britain. Pop trends. London: HMSO, winter 1986:46.

14 West Midlands Regional Health Authority. Ethnic minorities in the West Midlands Health Region: locations. January 1984:8, 63

15 OPCS. Population projections (area) 1983-2001. London: HMSO, 1986:6:3

16 Tunstall-Pedoe H, Clayton D, Morris JN, Brigden W,
McDonald L. Coronary heart attacks in East London. Lancet 1975;ii:833-8.

17 Donaldson LT, Taylor JB. Patterns of Asian and non-Asian morbidity in hospitals. BMJ 1983;286:949-51.

18 Balarajan R, Bulusu L, Adelstein AM, Shukla V. Patterns of mortality among migrants to England and Wales from the Indian subcontinent. BMJ 1984;289:1185-7.

19 McKeigue PM, Marmot MG, Adelstein AM, et al. Diet and risk factors for coronary heart disease in Asians in Northwest London. Lancet 1985;ii:1086-90.

20 Lowry PJ, Glover DR, Mace PJE, Littler WA. Coronary artery disease in Asians in Birmingham. Br Heart J 1984;52:610-3.

21 Sewdarsen $M$, Jialal I. Coronary heart disease in Indian overseas [Letter]. Lancet 1986;ii:159.

22 Mather HM, Keen H. The Southall Diabetes Survey: prevalence of known diabetes in Asians and Europeans. BMJ 1985;291:1081-4. 